\title{
Entre la experiencia y el saber. Los Viajes de Beatriz Sarlo*
}

\section{Between Experience and Knowledge. Viajes de Beatriz Sarlo}

Alberto Giordano ${ }^{\mathrm{a}}$

DOI: https://doi.org/10.11144/Javeriana.cl24.eesv

Universidad Nacional de Rosario, Argentina

albertogiordano59@gmail.com

ORCID: https://orcid.org/0000-0001-7372-3013

Recibido: 10 Octubre 2018

Aceptado: 07 Diciembre 2018

Publicado: 30 Diciembre 2020

\section{Resumen:}

Este artículo desarrolla una lectura crítica de Viajes. De la Amazonia a las Malvinas centrada en la valoración de la retórica autobiográfica de Beatriz Sarlo, de los modos en que su escritura testimonial articula narración y ensayo, experiencia personal y saber. Por una parte, se reconstruyen las estrategias de autofiguración que apuntan a sostener la imagen de la autora como moralista que ejerce la crítica de las costumbres contemporáneas - las del turismo como práctica de la cultura de masas, en general, y las del "turismo ideológico" que los jóvenes latinoamericanos practicaban hacia fines de los sesenta y comienzos de los setenta, en particular-. Por otra, se evalúa la eficacia de los recursos que le permiten a Sarlo trascender el narcisismo propio de la rememoración autobiográfica: el enmarque teórico — centrado en el concepto-valor de "salto de programa" - , la experimentación ensayística con los modos de la exposición — los del relato de viajes y los de la crítica ideológica - y la busca de un tono matizado, capaz de transmitir la coexistencia de afectos heterogéneos que no inhiban la posibilidad de que el pasado retorne en el presente como un proceso todavía en curso.

Palabras clave: Beatriz Sarlo, Viajes, retórica autobiográfica, autofiguración, experiencia y saber.

\section{Abstract:}

This paper develops a critical reading of Viajes. De la Amazonia a las Malvinas which focuses on the evaluation of Beatriz Sarlo's autobiographical rhetoric, the ways in which her testimonial writing articulates narration and essay, personal experience and knowledge. On the one hand, it reconstructs the strategies of self-figuration that aim to sustain the image of the author as a moralist who exercises criticism of contemporary customs (those of tourism as a practice of mass culture, in general, and those of "ideological tourism" that young Latin Americans practiced towards the end of the 1960s and beginning of the 1970s, in specific). On the other hand, it evaluates the success of the means by which Sarlo is able to transcend the narcissism typical of autobiographical remembrance: the theoretical framework (centered on the concept-value of "programme leap"), the essayistic experimentation with the styles of presentation (those of travel narratives and those of ideological criticism) and the search for a nuanced tone, able to transmit the coexistence of heterogeneous affections without inhibiting the possibility of a return to the past in the present as a process still in progress.

Keywords: Beatriz Sarlo, Viajes, autobiographical rhetoric, self-figuration, experience and knowledge.

Según los recuerdos de Sigrid Nunez (Siempre Susan 93) que convivió con ella y su hijo David algunos años, a Susan Sontag le encantaba ir al cine, varios días a la semana, y sentarse cerca de la pantalla, con el entusiasmo infantil propio de quien nunca ve televisión. No es raro entonces que Beatriz Sarlo la descubriese delante suyo, una tarde de 1985, en una sala del Upper Manhattan, mientras sobrellevaban airosas la proyección de Berlin Alexanderplatz. Durante el intervalo, la ensayista argentina se acercó discretamente a su par norteamericana para escuchar qué le comentaba a un amigo sobre la película. De regreso a la sala, buscó una ubicación próxima a la de Sontag, con ánimo de prolongar la excepcionalidad del momento. El relato de este encuentro, inédito hasta 2013, celebra sin imposturas los encantos del esnobismo intelectual; sobre el final, se resuelve en una máxima -- un salto de lo anecdótico a lo reflexivo-- que expone la ambigüedad de los recursos con los

Notas de autor

\footnotetext{
a Autor de correspondencia. Correo electrónico: albertogiordano59@gmail.com
} 
que debe contar el autobiógrafo si espera producir la deseable sensación de vida: "las experiencias inolvidables están hechas de materias perfectamente casuales, casi indiferentes" (Sarlo, "Sontag” 122).

Antes de comenzar la lectura de Viajes. De la Amazonia a las Malvinas, nos preguntábamos cuánto de esta exigencia literaria de narrar lo memorable ateniéndose a lo circunstancial habría subsistido en un relato orientado a reconstruir los modos en que la experiencia personal participaba, en los sesenta, de un universo de intereses colectivos. Nos preguntábamos también cómo habrían incidido sobre la retórica autobiográfica de Sarlo en el momento de escribir y encadenar los recuerdos de sus viajes juveniles, las reservas morales que manifestó hace apenas una década, en el contexto de un debate sobre cine documental, a propósito del recurso cada vez más frecuente a la primera persona en la cultura contemporánea, hasta qué punto esas creencias severas la habrían limitado, en caso de haberlas tenido presentes.

Cuando uno lee autobiografías literarias, que no sean las muy buenas, queda sumergido en una maraña de trivialidades. Como si la primera persona sólo pudiera ser aceptable si es redimida estéticamente. El yo pone un techo muy bajo a la escritura. (Sarlo, Tiempo pasado, 5)

Viajes no es una autobiografía, pero sí la articulación de secuencias autobiográficas modeladas por los impulsos básicos del género. En primer lugar, la voluntad de reconstruir un pasado personal memorable, digno de ser contado. El interés de la reconstrucción depende en buena medida de su valor documental, pero también de las destrezas retóricas para hacer que lo pasado reviva, e incluso se transforme en la escritura, más allá de los límites ideológicos y sentimentales que fija la memoria como principio constructivo. De la literatura (Saer o Benjamin, Barthes o Proust), Sarlo aprendió que el pasado, si inquieta el presente, es menos una presencia que pasó y podríamos reconstruir en tanto tal, que la huella de una tensión afectiva irresuelta, algo que continúa ocurriendo y transformándose de formas no siempre calculables, bajo la presión de lo que se espera o se desea del porvenir. La literatura sabe - los buenos críticos aprenden a actuar conforme a este saber, aunque sólo narren vivencias de lectura- que el funcionamiento de la memoria queda sujeto eventualmente, en el acto de la rememoración, a la imaginación, e incluso la invención autobiográfica, sin menoscabo de la intención de comunicar algo verdadero. En el final de "El salto de programa", el texto que funciona como introducción, Sarlo envuelve en una digresión ese saber sobre la plasticidad y la impropiedad del pasado al que pertenecemos, en el que no podemos dejar de pensar mucho tiempo después de ocurrido, cuando reconoce que los relatos de viaje que componen el libro no son "testimonios neutrales" de aquellos desplazamientos juveniles, sino recuerdos (imágenes) de "las formas en que la experiencia me modificó en cada momento" (Sarlo, Viajes 32). En su sentido fuerte, toda experiencia es de los límites del mundo en el que se individualiza la subjetividad, y es en ese sentido en el que la escritura autobiográfica querría registrarla para preservar su potencia modificadora. Como además del recuerdo intervino la escritura, las experiencias de los viajes juveniles de Sarlo podrían continuar modificando al sujeto de los desplazamientos — que es el de la rememoración y el del relato, si la lectura sabe imaginar pliegues desconocidos de lo que ocurrió y revivirlo a su manera-.

El otro impulso básico de la autobiografía que incide en los modos narrativos de Viajes es la voluntad de autofiguración según los valores, las disposiciones y las conductas que recortan determinados perfiles culturales con los que la autora querría que se la identifique ${ }^{1}$. Entre las imágenes de sí misma que construye Sarlo mientras compone la trama de los recuerdos, la más atractiva de ellas remite a una larga y espléndida tradición del pensamiento junto con el ensayo francés, la del moralista que ejerce la crítica de las costumbres contemporáneas desde la experimentación con las posibilidades de un estilo de intervención política idiosincrático ("política”, en el sentido etimológico, es decir, interesada por los asuntos de la polis, de la comunidad). Situado desde el punto de vista de ese estilo, el recurso a lo autobiográfico es un procedimiento que sutiliza los rigores de la crítica ideológica — demasiado apegada, por lo general, a paradigmas morales estereotipados, la vuelve más sensible a los matices-. Las costumbres contemporáneas que Sarlo pone a trasluz en Viajesson las del turismo en tanto desplazamiento programado por supersticiones que se busca 
confirmar. Más que en su versión obvia, como práctica de la cultura de masas, la mirada crítica se detiene en una variante sofisticada, el "turismo ideológico" hacia fines de los sesenta y comienzos de los setenta, cuando se viajaba "para seguir las vías de la revolución futura o para conocer a sus futuros protagonistas" $(221)^{2}$. Al espíritu de sutileza hay que atribuir el acierto de diferenciar al turistadel viajero en términos más complejos que los de una oposición simple. Si el primero viaja para confirmar lo que cree conocer — por eso "se precipita y pasa” (88) -, el segundo lo hace para explorar alguna dimensión de lo desconocido, de los otros y de sí mismo - por eso va despacio-. Pero en la modernidad, el turismo fija las condiciones culturales de cualquier viaje, todos somos, en principio, turistas, aunque no todos se conformen con ese destino trivial: "Muchos turistas soñamos con el salto de programa" (26), la ocurrencia de un episodio que precipite - como si de unas experiencias estéticas se tratara- el desprendimiento de las pautas culturales. El devenir viajero del turista es un sueño que acaso sólo se cumple en los recuerdos, después de regresar; con más intensidad si el relato, al evocar el suceso, revive la conmoción del salto más allá.

Incluso si no las tuvo presentes al concebir y desarrollar el proyecto, las reservas morales sobre las limitaciones del "giro subjetivo" en la crónica y el ensayo contemporáneos habrán incidido espectralmente sobre Sarlo al decidir abordar el entramado ideológico de una época desde lo intransferible de las experiencias personales ${ }^{3}$. Para conjurar los fantasmas de la trivialidad y el narcisismo autocelebratorio, recurrió en Viajes a un expediente formal sofisticado, en el que se articulan el enmarque teórico, la experimentación ensayística con los modos de la exposición (los del relato de viajes y los de la crítica ideológica) y la busca de un tono matizado, capaz de transmitir la coexistencia de afectos heterogéneos, para que la precisión conceptual y el acabado retórico no inhiban la posibilidad de que el pasado retorne en el presente como un proceso todavía en curso.

Por enmarque teórico no entendemos el recurso a un sistema de conocimientos y una metodología explicativa, pensamos, más bien, en los ejercicios argumentativos que ponen a prueba las potencias gnoseológicas y críticas de un concepto-valor, "el salto de programa", en la busca de una articulación coherente y no reductora de la experiencia con el saber. El "salto de programa" es lo que vuelve a un viaje interesante e irrepetible (digno de ser contado), la ocurrencia de algo imprevisto, un acontecimiento aleatorio - no siempre espectacular: "Muchas veces es un reconocimiento inesperado, una familiaridad impensada" (21) — en el que sucede el encuentro con algo no buscado, "un shock que desordena lo previsible, rompe el cálculo y, de pronto, abre una grieta [un intervalo suplementario] por donde aparece lo inesperado, incluso lo que no llegará nunca a comprenderse del todo" (15). En el relato de viaje, la narración del suceso inesperado le da a la historia autobiográfica un ligero golpe de incertidumbre que inquieta lo que la memoria cristalizó —diría Benjamin - como "recuerdo souvenir", una sacudida que mantiene activo el vínculo entre experiencia y falta de sentido y le da a la vida rememorada un suplemento de significación literaria.

El enmarque teórico que abre y cierra el libro subordina lo narrativo a lo ensayístico (lo cierra con una digresión existencial sobre las particularidades del relato de viaje, la dificultad para reencontrarse a través de la escritura de los recuerdos con ese otro que viajó). Si la narración es, como quiere Saer, un ejercicio sonámbulo que busca experimentar la suspensión del sentido, la reflexión ensayística le atribuye sentido a esa interrupción, le asigna un valor generalizable. El "salto de programa” es un concepto luminoso que revela el vínculo estructural entre viaje y aprendizaje: "se aprende lo que no se ha buscado deliberadamente, se encuentra una escena para la que no se tiene ningún elemento de interpretación: no se entiende lo que se ve o se lo entiende tarde" (26). El punto de vista del "salto de programa” recuerda que el aprendizaje auténtico (en su diferencia radical con la instrucción programada) es un viaje múltiple y aventurado a lo desconocido, una búsqueda para la que nunca se cuenta con recursos suficientes, que responde menos a la voluntad de conocer que a la violencia del encuentro con algo imprevisto que da que pensar ${ }^{4}$.

La experimentación con las convenciones del relato de viaje y los protocolos de la crítica ideológica se puede apreciar en la forma de distribuir los capítulos. La sección central de Viajes - hubiese podido constituir por sí misma un libro- agrupa los recuerdos de los desplazamientos por Latinoamérica, a fines de los sesenta 
y comienzos de los setenta, los que remiten a las vivencias del "turismo ideológico". En la puna jujeña y el altiplano boliviano, en las minas de Oruro a las que descendieron, en una aldea de jíbaros en la Amazonia peruana, pero también en Brasilia, emblema del desarrollismo y la modernidad, los jóvenes exploradores encontraron lo que esperaban, lo que buscaron, por un camino de privaciones y esfuerzos, para legitimar sus creencias revolucionarias a través de la confrontación con la "empírea": lo "real", tal y como esas mismas creencias lo hacían visible. "La ideología es inconmovible, para las buenas y las malas causas" (103). La sentencia, pieza clave en el discurso del moralista, introduce la perspectiva problemática de otros aprendizajes, adquiridos en la madurez, los que tienen que ver con la conveniencia de impugnar las valoraciones del sentido común. En cada locación a la que accedieron por la vía regia de la depuración espiritual —es decir, el sacrificio de las comodidades pequeñoburguesas - los jóvenes comprobaron que el futuro de las inevitables transformaciones sociales pasaría por Latinoamérica y que sus pobres estaban predestinados a protagonizar el mítico "Gran Cambio". En el encuentro con lo otro, la ceguera es de rigor, si actuamos intimidados por la voluntad de reconocimiento. El relato de estos viajes documenta la fuerza persuasiva del latinoamericanismo "como deber ideológico" (120), pero también desborda la condición testimonial, en el camino de lo novelesco, cuando da cuenta de los saltos de programa que desviaron el curso de los desplazamientos pedagógicos hacia lo entrevisto o lo desconocido. El descubrimiento de una "iconografía sorprendente" (90) sobre las paredes de una iglesia perdida, donde sólo esperaban encontrar un tesoro de mayor prestigio, aunque menos enigmático: "pintura popular". La revelación tardía - el salto ocurre sobre todo en los recuerdos- de que los aborígenes amazónicos con los que convivieron amablemente pertenecían a una etnia jíbara. Cuando el relato absorbe la fuerza disruptiva de estos episodios, antes de que la reflexión la encauce a través del diálogo con los saberes que interpela cada viaje ${ }^{5}$, el pasado difiere ligeramente respecto de sí mismo y la vida de la autobiógrafa recupera, por un instante —el del placer de la lectura-, su condición errática.

El primero y el último capítulo, los recuerdos de las vacaciones infantiles en Deán Funes y la crónica del viaje a las Malvinas en ocasión del referéndum del 2013, parecen en principio anexos complementarios que vendrían a dar mayor peso y consistencia al libro, pero en una segunda lectura se advierte que su inclusión responde a un propósito compositivo más exigente: instalar en el comienzo y el final un máximo de intensidad afectiva, asociado a la afirmación de lo infantil como supervivencia misteriosa, para que el acabado retórico no se desentienda del vínculo entre escritura e indeterminación (lo imprevisto como suspensión renovadora del sentido). "El viaje original" anticipa lo que "Una extranjera en las islas" impone como verdad en acto (sin revelar ni demostrar nada): que en todo viaje, cuando el salto de programa suspende al viajero entre lo que sabe y lo que ignora, ocurre el retorno de algo originario, que el vínculo entre viaje e infancia es esencial. Se dice que nunca llegamos tan lejos como cuando desconocemos hacia dónde vamos. Sarlo tuvo que viajar a Malvinas, dejándose llevar por "una improvisación impulsiva” (176), para reencontrarse con algunos sonidos infantiles olvidados (el acento del inglés que se hablaba en su colegio de Palermo), para recuperar la infancia como porvenir de toda experiencia auténtica, en la que las palabras entredicen los afectos silenciosos que las preceden. Más cerca de Proust que de Saer (¿qué crítico, si barthesiano, no mantiene una reserva anacrónica de confianza en el poder de la literatura? $\left.{ }^{6}\right)$, la epifanía de la entonación olvidada reanima, por el camino del recuerdo involuntario, la presencia intangible, pero cierta, de un mundo de imágenes e identificaciones imprevisto.

Dos notas de lectura sobre estos capítulos que nos seguirán dando que pensar. En el comienzo de "El viaje original", Sarlo recuerda que conoció el mar relativamente tarde, si se la compara con sus compañeras de colegio.

A ellas les ocultaba esa falta en mi formación como si hubiera sido mi culpa. Ellas mencionaban lugares como "Playa Grande" y el "Ocean”. Yo disimulaba. Me era imposible imaginar qué querían decir con "la carpa” (¿exploraban esa Playa Grande y dormían allí ?) ni "Los Troncos" (¿era un barrio de casas de madera, tipo leñador?). (36-37) 
El auténtico viaje original, la matriz de todos los desplazamientos que confrontan al sujeto con algunos de sus límites, es el de la niña a través de lo extraño de la propia lengua, un viaje en el que el salto de programa y la familiaridad con lo imprevisto son la regla. La segunda nota: el relato del viaje a Malvinas — su intensidad es directamente proporcional a la del trauma que revive (el aislamiento, en medio de la escalada nacionalista, durante la guerra del 82) - está estructurado como un ensayo: Sarlo lo escribió para conocer, más que para referir, las razones secretas — no las coartadas - que la impulsaron a viajar. La forma exploratoria, que configura al desplazamiento como errancia, revela otro vínculo esencial: todo ensayo se estructura como un viaje a lo desconocido, en el que los saltos de la argumentación y la disposición a la ocurrencia imprevista son principios constructivos?

La intensidad afectiva y literaria de los capítulos complementarios se explica no sólo por el aura infantil que rodea la aparición de ciertos recuerdos, sino también por las proyecciones de una vivencia novelesca que Enrique Vila-Matas identificó en El viaje vertical: "Cuando viajas con alguien siempre tiendes a mirar lo que te rodea con extrañeza mientras que, cuando viajas solo, el extraño eres tú" (32). Desprendida de sus grupos de referencia, en tránsito, la subjetividad viajera queda expuesta al reconocimiento o la experiencia de su íntima extraterritorialidad. En los recuerdos infantiles de los veraneos en Deán Funes, entre lo que anticipa por la vía del reconocimiento la sensibilidad y la ética adultas (el estoicismo como barrera contra la frivolidad, encarnado en la figura del casero húngaro, Lajos Kovacic), se entredicen las ambigüedades de la pertenencia familiar (la mezcla de fastidio y orgullo por haber tenido unos Reyes Magos que actuaban como pedagogos). ${ }^{8}$ También en el viaje solitario a Malvinas, el salto más allá del reconocimiento especular duplica, discretamente, los estremecimientos del salto de programa: el descubrimiento de la simpatía con el "espíritu de independencia" y el "temple sacrificado" de los isleños (206), a los que idealiza como personajes de una novela de aventuras para sostener la idealización del estoicismo como ética superior, propicia la experiencia de otra tensión irresoluble, la del intelectual que reniega de cualquier nacionalismo sin renunciar a la identificación con una nacionalidad.

La coexistencia de afectos heterogéneos - de su manifestación depende tanto que el pasado retorne con vida, como que la retórica autobiográfica desborde las limitaciones del género- es legible discontinuamente en el tono que modula la rememoración de los viajes latinoamericanos. Por un lado - el que conduce a las autofiguraciones del crítico como moralista - asistimos a un ejercicio constante y filoso de autoironía que expone el desapego actual de cualquier forma de populismo, lo mismo que de cualquier creencia escatológica. El distanciamiento irónico articula lo anecdótico de las vivencias autobiográficas con un horizonte de debates políticos, sobre los malentendidos, muchas veces trágicos, de las ideologías redencionistas, que todavía inquietan el presente. En la página 99, leemos: "Empiristas ingenuos, pensábamos que ver era conocer. [...] y avanzábamos como turistas ideológicamente automáticos: cuanta más pobreza encontrábamos, más cerca nos creíamos de la clave que perseguíamos en el viaje”. Más adelante, una ocurrencia ingeniosa precisa los contornos del voluntarismo juvenil: "Nuestra ideología era optimista y, como personajes de novelas filosóficas del siglo XVIII, nos deslizábamos interpretando todo con una especie de bonhomía radical” (Sarlo, Viajes 103). Al entusiasmo pueril de aquellos viajeros, desde una extensa nota final, Sarlo opone el "pesimismo del intelecto" (248), de Gramsci, entendido como un grado superior del realismo político.

Casi en sordina, hay otra tonalidad que convive con el efecto retroactivo de irrisión; llamémosla "sentimental", ya que expresa, no la distancia, sino la proximidad de quien recuerda en la escritura con un pasado al que, de alguna forma, todavía pertenece. Más acá de la arrogancia y el optimismo ingenuo, en la joven que descendió a una mina boliviana, la que resistió el frío del altiplano en la caja de un camión y convivió en armonía entre aborígenes amazónicos, reconocemos, hacia atrás y hacia adelante, el espíritu aventurero y sacrificado de los malvinenses y la elección originaria del estoicismo como estilo de vida soberano. 


\section{Referencias}

AA.VV. "Cine documental: la primera persona”. Punto de Vista, n. ${ }^{\circ}$ 82, 2005, pp. 3-7.

Barthes, Roland. "Chateaubriand: Vida de Rancê". El grado cero de la escritura. Nuevos ensayos críticos. Traducido por Nicolás Rosa, Siglo XXI, 1983.

Deleuze, Gilles. Proust y los signos. Traducido por Francisco Monge, Anagrama, 1972.

Giordano, Alberto. "Vida y obra. Roland Barthes y la escritura del diario". Analecta, n. ${ }^{\circ}$ 5, 2012, pp. 129-141.

Molloy, Sylvia. Acto de presencia. La escritura autobiográfica en Hispanoamérica. Fondo de Cultura Económica, 1996. Nunez, Sigrid. Siempre Susan. Recuerdos de Susan Sontag. Traducido por Mercedes Cebrián, Errata Naturae, 2013.

Sarlo, Beatriz. "Barthesianos de por vida" y "Sontag en un cine". Plan de operaciones. Sobre Borges, Benjamin, Barthes y Sontag. Universidad Diego Portales, 2013, pp. 11 y 119-122.

Sarlo, Beatriz. "Del otro lado del horizonte". Boletin/9,, 2001), pp.16-31.

Sarlo, Beatriz. Tiempo pasado. Cultura de la memoria y giro subjetivo. Una discusión. Siglo XXI, 2005.

Sarlo, Beatriz. Viajes. De la Amazonia a las Malvinas. Seix Barral, 2014.

Vila-Matas, Enrique. El viaje vertical. Anagrama, 1999.

\section{Notas}

* Artículo de revisión.

1 En un estudio ya clásico sobre el género, Sylvia Molloy (Acto de presencia) define y precisa los alcances metodológicos del concepto de autofiguración.

2 Como el que viaja para refrendar lo que leyó en un folleto o una guía, el turista ideológico busca en la realidad "un documento probatorio" (Sarlo, Viajes 104) de sus lecturas políticas. Sin los privilegios de la distancia irónica como beneficio del paso del tiempo, el Diario de mi viaje a China, de Roland Barthes, es un testimonio —irónico, de todos modos- de lo disciplinados y tediosos que podían resultar aquellos viajes políticos para un intelectual de izquierda no tan fascinado con el espectáculo de su buena conciencia. En Giordano ("Vida y obra"), ensayamos un comentario de las vivencias barthesianas del turisteo ideológico.

3 En su polémico Tiempo pasado. Cultura de la memoria y giro subjetivo. Una discusión, Sarlo evalúa con inteligencia las limitaciones del recurso a lo vivencial y la primera persona autobiográfica en el discurso actual de las humanidades y las ciencias sociales.

4 En esta imagen del aprendizaje ligada a la "coacción” y el "azar" como factores condicionantes, se encontrarán resonancias de la lectura deleuziana de Proust (Deleuze, Proust 25).

5 El diálogo múltiple con los múltiples saberes que convoca la experiencia viajera — de la etnografía a la historia cultural, pasando por la arquitectura, la sociología y, claro, la crítica literaria - se resuelve con eficacia y discreción en las notas dispuestas al final del libro, algunas de extraordinario valor documental, como la número 72 (246-260), que reconstruye los debates dentro de la izquierda nacional durante de la guerra de Malvinas.

6 Una breve nota incluida en Plan de operaciones (11), "Barthesianos de por vida", condensa las razones de la identificación con el crítico francés.

7 En "Del otro lado del horizonte" (2001), Sarlo explora conceptualmente los modos del ensayo como búsqueda del saber métodicamente ametódica.

8 Hecho de la materia perfectamente casual y casi indiferente en la que se encarnan las experiencias inolvidables, el recuerdo de un tío "hermoso, con un sombrero rancho y traje claro de los llamados palmbeach, vestido como un dandy ien Deán Funes!” (Sarlo, Viajes 41), el tío que los recibió en la estación de trenes la primera vez que llegaron al pueblo, retorna de la infancia porque sí, innecesario, desprendido de cualquiera de los usos que se le pueda dar a la memoria, para imprimirle al relato la serena intensidad de lo novelesco. En la ocurrencia de estos detalles inútiles, que se imponen al lector porque no imponen más que la dicha de la impresión circunstancial, Barthes ("Chateaubriand" 164) situaba "el acto que separa al escritor del escribiente".

\section{Licencia Creative Commons CC BY 4.0}


Cómo citar este artículo: Giordano, Alberto. "Entre la experiencia y el saber. Los Viajes de Beatriz Sarlo". Cuadernos de Literatura, vol. 24, 2020. https://doi.org/10.11144/Javeriana.cl24.eesv 